\title{
Prenatal Genetic Screening and Diagnostic Testing: Assessing Patients' Knowledge, Clinical Experiences, and Utilized Resources in Comparison to Provider's Perceptions
}

\author{
${ }^{1}$ Department of Obstetrics and Gynecology, University of South \\ Florida Morsani College of Medicine, Tampa, Florida \\ ${ }^{2}$ Department of Obstetrics and Gynecology, University of \\ Washington School of Medicine, Seattle, Washington \\ 3 Department of Obstetrics and Gynecology, Division of Maternal \\ Fetal Medicine, The George Washington University School of \\ Medicine and Health Sciences, Washington, Dist. of Columbia
}

Arlin Delgado, $\mathrm{MD}^{1}$ Jay Schulkin, $\mathrm{PhD}^{2}$ Charles J. Macri, $\mathrm{MD}^{3}$

Address for correspondence Arlin Delgado, MD, 2 Tampa General Circle, STC 6th Floor, Tampa, FL 33606

(e-mail: arlindelgado@usf.edu).
AJP Rep 2022;12:e27-e32.

\begin{abstract}
Keywords

- patient-provider communication

- pregnancy related care

- genetic counseling

- genetic screening

- genetic testing

Objective This survey study aimed to assess patient knowledge, clinical resources, and utilized resources about genetic screening and diagnostic testing.

Study Design A one-time anonymous paper survey was distributed to 500 patients at a major urban obstetrics and gynecology department, and an online survey was sent to 229 providers. Descriptive statistics and chi-squared analyses were performed.

Results In all, 466 of 500 patient surveys were completed, and 441 analyzed (88.2\% response rate). Among providers, 66 of 229 (29.0\% response rate) responded. Patients were on average 32 years old, 27 weeks pregnant, and most often reported a graduate degree level of education (47.4\%). Over $75 \%$ of patients reported accurate knowledge of basic genetic statements. Patients reported that discussing screening and diagnostic testing with their provider was significantly associated with properly defining screening and diagnostic testing $(p<0.001)$. Less than $10 \%$ of patients reported providers distributing web/video links, books, or any other resource; however, patients most often independently accessed web links (40.1\%).

Conclusion Our findings suggest a positive impact from patient and provider discussions in office on patient knowledge and understanding. Discrepancies between educational resources distributed in the clinic and individually accessed resources highlight possible areas of change. Future work should evaluate and implement differing resources to increase patient knowledge.
\end{abstract}

received

February 17, 2021 accepted after revision October 8, 2021
DOI https://doi.org/ 10.1055/s-0041-1742236. ISSN 2157-6998.

\footnotetext{
(C) 2022. The Author(s).

This is an open access article published by Thieme under the terms of the Creative Commons Attribution-NonDerivative-NonCommercial-License, permitting copying and reproduction so long as the original work is given appropriate credit. Contents may not be used for commercial purposes, or adapted, remixed, transformed or built upon. (https://creativecommons.org/ licenses/by-nc-nd/4.0/) Thieme Medical Publishers, Inc., 333 Seventh Avenue, 18th Floor, New York, NY 10001, USA
} 
The last two decades have ushered in an explosion of new genetic screening and diagnostic testing that provides patients with more accurate and specific information about their health. Due to these advances, prenatal genetic screening and testing has become increasingly common in obstetric health care with multiple new recommendations by the American College of Obstetricians and Gynecologists $(\mathrm{ACOG})^{1-4}$ to guide providers. Furthermore, these novel technological advances in genetic screening require wellinformed patients to understand the results and implications of the tests provided

Despite this increase in knowledge of genetic services and research, there remains a deficit in understanding the applications of these services on the patient when considering screening tests. ${ }^{5}$ In fact, studies show women who underwent genetic screening and testing later report being unaware of the purpose of the test and what the results mean. ${ }^{6}$ Inadequate understanding of the implications of genetic services can impact a patient's health and their decisionmaking, especially in the context of prenatal care. ${ }^{7}$

There is currently limited research regarding prenatal testing and patient education. Research shows there is a lapse in communication between providers and patients on genetic screenings. For example, in studies with Mexican origin patients, poor communication resulted in refusal of amniocentesis in pregnant women. ${ }^{8}$ This observed lack of communication may be further compounded by providers' expressed need for additional education and guidance in patient education of the new tests, like the cell-free deoxyribonucleic acid (cfDNA) screening. ${ }^{9}$ These studies successfully highlight the lack of adequate patient education on specific genetic screening tests like amniocentesis and cfDNA, but fail to provide data on the pregnant women's knowledge of genetic tests and how they receive information.

Therefore, this survey study aims to assess patient knowledge of genetic screening and diagnostic testing, evaluate the educational resources patients currently use from perspective of patients and providers, and identify areas to improve clinical resources on genetic testing education to improve the patient-provider communication in prenatal care.

\section{Methods}

Patient and providers at a major urban obstetrics and gynecology (OBGYN) department were offered the opportunity to complete a one-time anonymous survey. Patient surveys were distributed during clinic visits to all patients presenting for a prenatal-related visit (ultrasound visit, prenatal checkup, or routine nonstress test visit). Provider surveys were distributed using the clinic listserv via Qualtrics with one initial distribution and three subsequent reminder e-mails, approximately 3 to 4 weeks apart. Providers that received the e-mail included physicians (resident and nonresident), nurse practitioners, registered nurses, genetic counselors, medical assistants, and licensed practical nurses; however, there were no responses identified as licensed practical nurses. This study was approved by the George Washington Univer- sity institutional review board, and in collaboration with the Pregnancy Related Care Research Network (PRCRN).

\section{Patient Surveys}

The patient demographics included age, race, level of education, and current trimester. To understand clinical experiences, patients were asked if they had had prior screening and diagnostic testing in an earlier pregnancy, recalled discussions with providers during this pregnancy, or were interested in various screening and testing options (first trimester blood work and ultrasound, cfDNA blood work, cystic fibrosis carrier blood work, hemoglobin electrophoresis, sickle cell trait carrier blood work, thalassemia carrier blood work, second trimester blood work, chorionic villus sampling, amniocentesis, maternal serum $\alpha$-fetoprotein, or anatomy ultrasound). Patients were also asked if they had discussed the difference between screening and diagnostic testing with a provider, had met with a genetic counselor, and if these health care professionals were able to answer their questions using a 3-point Likert scale ("Unable to answer any of my questions," "Answered some, but not all my questions," and "Answered all my questions").

To assess patient knowledge about the association between genes, chromosomes, the body, as well as disease, we utilized 6 items from a 16-item survey previously utilized by Haga et $\mathrm{al}^{5}$ and Jallinoja and Arro ${ }^{10}$ in the general population, as well Calsbeek et $\mathrm{al}^{11}$ in a nonobstetric patient population. The full 16-item survey was not utilized due to concerns for survey length. These questions focused on general geneticsrelated knowledge and the health implications using a 5point Likert scale (from "strongly disagree" to "agree"). The six statements adapted from prior work are listed in -Table 1. All other knowledge-based statements, such as defining genetics invasive testing options, were not adapted from prior work. Patient responses were then binned into "correct," "incorrect," and "unsure" using the following key: strongly agree/agree $=$ correct; neutral = unsure; and strongly disagree/disagree $=$ incorrect.

Table 1 General patient knowledge of genetics

\begin{tabular}{|l|l|}
\hline Survey questions & $\begin{array}{l}\text { Current population } \\
(\mathrm{N}=\mathbf{4 6 1}), \% \text { correct }\end{array}$ \\
\hline $\begin{array}{l}\text { One can see a gene } \\
\text { with a naked eye }\end{array}$ & 80.5 \\
\hline A gene is a disease & 85.7 \\
\hline A gene is part of a chromosome & 74.8 \\
\hline Genes are inside cells & 81.4 \\
\hline $\begin{array}{l}\text { Healthy parents can have a } \\
\text { child with a hereditary disease }\end{array}$ & 83.2 \\
\hline $\begin{array}{l}\text { The carrier of a disease gene } \\
\text { may be completely healthy }\end{array}$ & 83.4 \\
\hline
\end{tabular}

Sources: Adapted from Haga et al, ${ }^{5}$ Jallinoja and Aro, ${ }^{10}$ and Calsbeek et al. ${ }^{11}$ 


\section{Provider Surveys}

The provider demographics included age, type of provider, primary specialty, race/ethnicity, and years in clinical practice. Provider knowledge is discussed at length in prior published work. ${ }^{12}$

\section{Patient-Provider Comparisons}

Both patients and providers were asked to recall in-office discussions, distribution of several resources in office, and to interpret the usefulness of proposed educational tools related to genetic screening and diagnostic testing using a 3-point Likert Scale (“not useful," "useful," and "very useful").

All data were analyzed using IBM SPSS Statistics. Descriptive statistics and chi-squared analysis of results are reported.

\section{Results}

\section{Patient Results}

A total of 500 patient surveys were distributed, of which 466 were completed and 441 were analyzed after assessing for $\geq$

Table 2 Patient and provider demographics

\begin{tabular}{|c|c|c|c|}
\hline & & Provider, $\boldsymbol{n}(\%)$ & Patient, $n$ (\%) \\
\hline \multicolumn{2}{|l|}{ Age $(y)$} & $43.3 \pm 12.7$ & $32.1 \pm 5.4$ \\
\hline \multicolumn{2}{|l|}{ Gender: male/female } & $3(5.1) / 52(88.1)$ & $-/ 441(100)$ \\
\hline \multirow[t]{6}{*}{ Race/ethnicity, $n(\%)^{\mathrm{a}}$} & Hispanic/Latino & $3(5.1)$ & $19(4.4)$ \\
\hline & Caucasian & $32(54.2)$ & $207(47.5)$ \\
\hline & Asian & $5(8.5)$ & $27(6.2)$ \\
\hline & African American & $17(28.8)$ & $164(37.6)$ \\
\hline & American Indian/Native Alaskan & - & $2(0.5)$ \\
\hline & Multiracial & $1(1.7)$ & $16(3.7)$ \\
\hline \multicolumn{4}{|l|}{ Patient specific } \\
\hline \multicolumn{2}{|l|}{ Gestational age (wk) } & - & $27.9 \pm 9.5$ \\
\hline \multicolumn{2}{|l|}{ Discussion in prior pregnancy } & - & $168(38.1)$ \\
\hline \multicolumn{2}{|c|}{ Visited with genetic counselor } & - & $210(47.8)$ \\
\hline \multirow[t]{5}{*}{ Highest level of education } & Not reported & - & $5(1.1)$ \\
\hline & Grade school & - & $6(1.4)$ \\
\hline & High school & - & $98(22.2)$ \\
\hline & College degree & - & $123(27.9)$ \\
\hline & Graduate degree & - & $209(47.4)$ \\
\hline \multirow[t]{6}{*}{ Clinic visit reason } & Prenatal visit & - & $237(53.7)$ \\
\hline & Ultrasound visit & - & $87(19.7)$ \\
\hline & Genetic counseling & - & $5(1.1)$ \\
\hline & Other reasons $^{\mathrm{b}}$ & - & $6(1.4)$ \\
\hline & Multiple visits in $1 \mathrm{~d}$ & - & $81(18.4)$ \\
\hline & Antenatal testing & - & $26(5.9)$ \\
\hline \multicolumn{4}{|l|}{ Provider specific } \\
\hline \multicolumn{2}{|c|}{ Clinical years in practice (average \pm standard deviation) } & $12.2 \pm 12.1$ & - \\
\hline \multirow[t]{7}{*}{ Type of provider } & Nonresident medical doctor & $16(27.1)$ & - \\
\hline & Resident medical doctor & $5(8.5)$ & - \\
\hline & Nurse practitioner & $1(1.7)$ & - \\
\hline & Certified midwife & $8(13.6)$ & - \\
\hline & Genetic counselor & $2(3.4)$ & - \\
\hline & Medical assistant & $8(13.6)$ & - \\
\hline & Administrative assistant & $16(27.1)$ & - \\
\hline
\end{tabular}

a Multiple response variable; therefore, total \% of responses is more than $100 \%$.

bOther reasons: symptomatic follow-up, high-risk consult. 
$75 \%$ survey completion (88.2\% response rate). On average, patients were 32 years old, 27 weeks pregnant, and most often reported a graduate degree level of education (47.4\%), with those identifying as Caucasian with the highest reported graduate degree level (70\%). Patients most often presented for a routine prenatal visit (53.7\%). A majority of patients selfidentified as Caucasian/White (47.5\%), and then as African American/Black (37.6\%). In all, 38.1\% reported screening and diagnostic testing in a prior pregnancy; however, $84.6 \%$ reported conversations about genetic screening with providers during their current pregnancy (-Table 2 ). Of the
$47.8 \%$ of patients who reported meeting with a genetic counselor, $56.7 \%$ reported having all their questions answered.

At least $60 \%$ of patients were able to accurately answer general genetics-related screening and diagnostic testing questions, except for defining aneuploidy (30.4\%; - Fig. 1). If a patient reported discussing screening and diagnostic testing with their provider, they were significantly more likely to properly define screening and diagnostic testing $(p<0.001)$.

Patients reported accessing educational resources independently, with the most common resource being web

\section{Patient General Knowledge Regarding Genetics, Screening, and Diagnostic Testing}

Amniocentesis and Chorionic villous sampling are invasive...

A diagnostic test tells you the whether you baby actually...

A screening test tells you the chance of your baby having a...

Screening and diagnostic tests are not really different and...

Aneuploidy is a condition in which a baby either has...

The carrier of a disease gene may be completely healthy

Healthy parents can have a child with a hereditary disease

Genes are inside cells

A gene is part of a chromosome

A gene is a disease

One can see a gene with the naked eye.

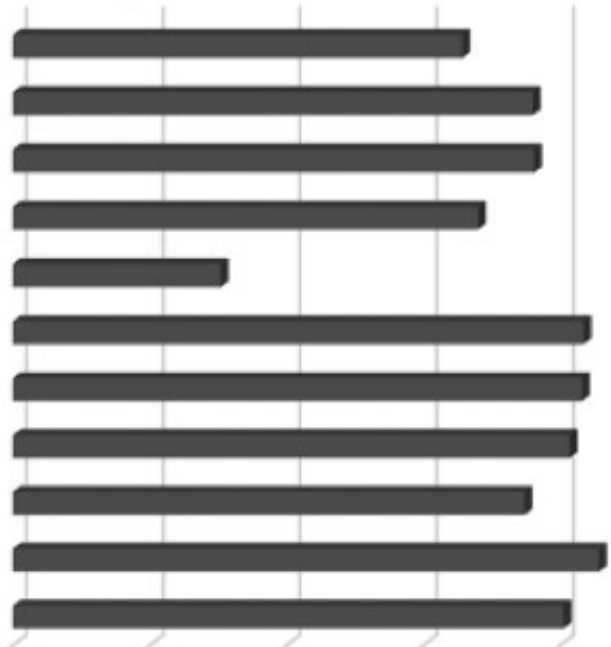

0

20

Proportion Correct (\%)

80

100

Fig. 1 Proportion of patients who correctly identified each statement. Proportions are presented on the horizontal axis with the statements presented on the vertical axis.

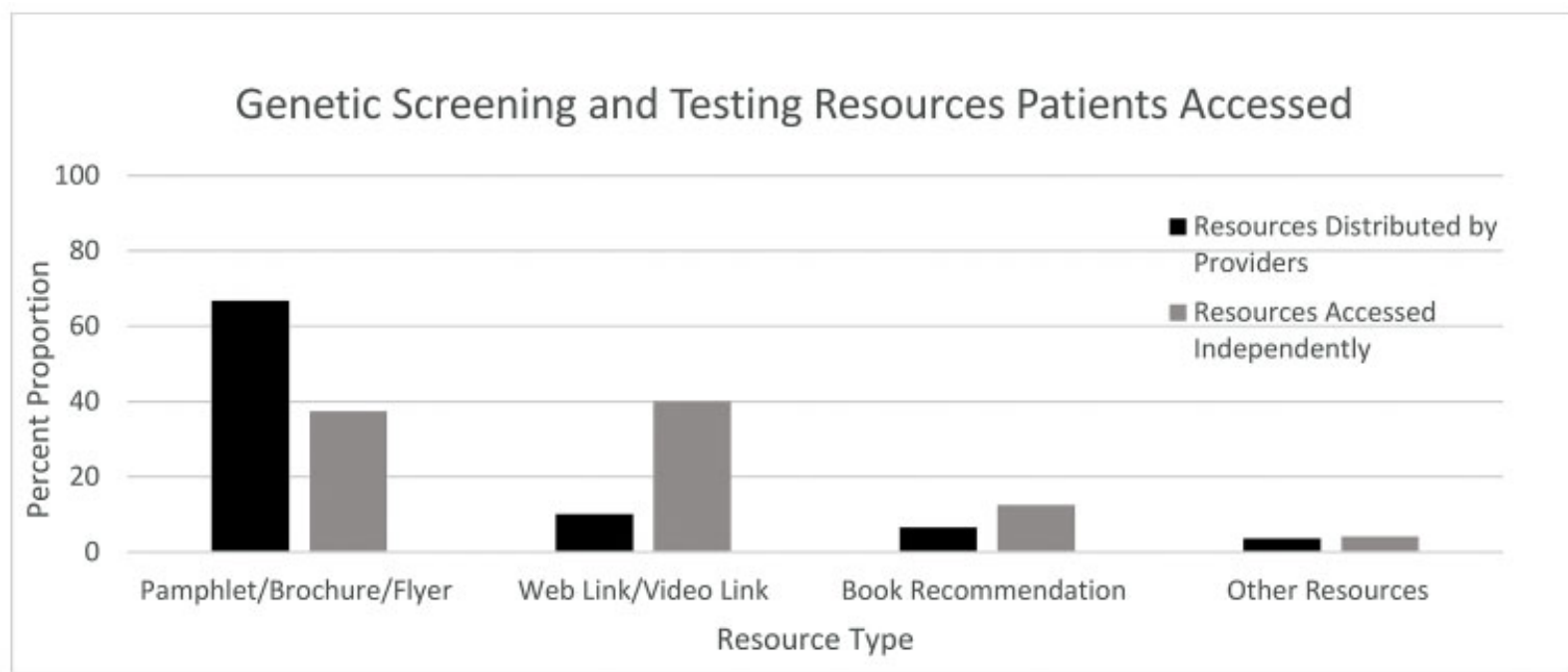

Fig. 2 Proportion of patients who reported receiving or accessing an educational tool by type of resource. Proportion of patients who accessed a resource by percentage on the vertical axis and type of resource listed on the horizontal axis. 
links/video (40\%), followed by pamphlets/brochures (37.1\%; -Fig. 2).

\section{Provider Results}

A total of 229 providers were sent online surveys via e-mail, and 66 responses were completed (response rate 29\%). From the 66 provider responses, 59 completed more than $50 \%$ of the survey. A majority (88.1\%) were females, on average 41 years old, and in practice an average of 12 years (-Table 2 ).

\section{Patient and Provider Comparison}

Patients and providers reported receiving and distributing paper resources (pamphlets/flyers/brochures) most often ( 66.7 and $90 \%$ at one or more visits, respectively). Less than $10 \%$ of participants reported providers distributing web or video links, books, or any other resource; however, patients most often independently accessed web links (40.1\%).

When questioned whether brochures or pamphlets, discussions with providers, discussions for reasons for a genetic counseling referral, group education classes, or online education would be useful, all but one option was perceived to be useful $80 \%$ or more of the time by patients. Meanwhile, providers found all resources useful over $85 \%$ of the time. The largest discrepancy was of the perceptions of group education classes with less than half the patients (47.6\%) perceiving it as useful, but majority of providers found it useful (75.9\%; - Table 3).

\section{Discussion}

A majority of patients are well informed on basic genetic concepts and were able to distinguish between the defini- tions of a screening and a diagnostic test. Patients who discussed screening and diagnostic testing were more likely to correctly define the terms, supporting counseling during provider visits is beneficial to patient's understanding of genetic screening and testing.

These results support the continuation of productive and educational conversations between patients and providers. However, when compared with a similar demographic population, patients were still less knowledgeable in genetics questions highlighting current measures may not be enough at a time when knowledge is necessary to make informed health decisions.

To find better ways to increase patient knowledge, the comparison of resources patients received from providers and the resources accessed individually shows a window of opportunity in which providers could create new effective and efficient tools for clinical practice to better engage patients. Furthermore, the discrepancies between patient and provider perceptions, seen largest with the idea of group classes, highlight where providers should consider increasing efforts (utilizing differing media and private discussions vs. group settings) for patient counseling. This patient perception may also only serve to emphasize the personalized needs and privacy associated with genetic screening and diagnostic testing.

However, it is critical to understand that the patient demographic captured in this survey study may not be generalizable to the general population-as we had a significantly large number of patients reporting a graduate degree or higher, compared with prior U.S. published census data. ${ }^{13}$ Additionally, the large number of genetic counselor visits reported may also not be generalizable to the general prenatal population due to the varying institutional practices as

Table 3 Patient and provider recall access to and distribution of resources

\begin{tabular}{|c|c|c|c|c|}
\hline Provider-reported distribution & Never (\%) & One or more visits (\%) & $\begin{array}{l}\text { Patient reported } \\
\text { receiving (\%) }\end{array}$ & $\begin{array}{l}\text { Patient independently } \\
\text { accessed (\%) }\end{array}$ \\
\hline Pamphlet/brochure/flyer & 10 & 90 & 66.7 & 37.4 \\
\hline Web link/video link & 66.7 & 33.3 & 10 & 40.1 \\
\hline Book recommendations & 86.7 & 13.3 & 6.6 & 12.5 \\
\hline Other resources & 77.8 & 22.2 & 3.6 & 4.1 \\
\hline Verbal discussions & - & 100 & 81.8 & - \\
\hline \multicolumn{3}{|l|}{ Provider-perceived usefulness } & \multicolumn{2}{|l|}{$\begin{array}{l}\text { Patient-perceived } \\
\text { usefulness }\end{array}$} \\
\hline \multicolumn{2}{|c|}{$\begin{array}{l}\text { Discussion regarding indications for genetic } \\
\text { counseling referral }\end{array}$} & 93.1 & 86.2 & - \\
\hline \multicolumn{2}{|c|}{$\begin{array}{l}\text { Informational brochure/pamphlets inside the } \\
\text { prenatal folder }\end{array}$} & 89.7 & 87.5 & - \\
\hline \multicolumn{2}{|c|}{$\begin{array}{l}\text { Having more discussions in the office with your } \\
\text { provider }\end{array}$} & 89.7 & 85 & - \\
\hline \multicolumn{2}{|c|}{$\begin{array}{l}\text { Group education class on genetic screening } \\
\text { and diagnostic tests }\end{array}$} & 75.9 & 47.6 & - \\
\hline \multicolumn{2}{|c|}{$\begin{array}{l}\text { Online education resource for review in your } \\
\text { home }\end{array}$} & 93.1 & 80.5 & - \\
\hline
\end{tabular}


well as availability of genetic counselors. These two factors may lead to falsely conceived higher levels of genetic knowledge than other populations. Furthermore, recall bias may also lead to inaccurate responses by patients and providers alike.

Utilizing this information, future research should study whether implementing educational tools via technological tools, like QR codes, into the waiting room, and in clinic, in congruence with patient-identified "usefulness" (i.e., web links/videos) would increase patient knowledge of genetic screening and diagnostic testing.

\section{Funding}

The Pregnancy-Related Care Research Network (PRCRN) is supported by the Health Research and Services Administration Grant UA6MC31609.

\section{Conflict of Interest}

There are no conflicts of interest; however, Dr. Schulkin is directly associated with the Pregnancy-Related Care Research Network (PRCRN). The PRCRN is supported by the Health Research and Services Administration Grant UA6MC31609.

\section{Acknowledgments}

We would like to acknowledge Raina Kaji for her assistance in the completion of this research project.

\section{References}

1 Committee opinion no. 640: cell-free DNA screening for fetal aneuploidy. Obstet Gynecol 2015;126(03):e31-e37

2 Committee opinion no. 693: counseling about genetic testing and communication of genetic test results. Obstet Gynecol 2017;129 (04):e96-e101
3 Practice bulletin no. 163 summary: screening for fetal aneuploidy. Obstet Gynecol 2016;127(05):979-981

4 Committee on Genetics. Committee opinion no. 690: carrier screening in the age of genomic medicine. Obstet Gynecol 2017;129(03):e35-e40

5 Haga SB, Barry WT, Mills R, et al. Public knowledge of and attitudes toward genetics and genetic testing. Genet Test Mol Biomarkers 2013;17(04):327-335

6 Colicchia LC, Holland CL, Tarr JA, Rubio DM, Rothenberger SD, Chang JC. Patient-health care provider conversations about prenatal genetic screening. Obstet Gynecol 2016;127(06): 1145-1152

7 Christensen KD, Jayaratne TE, Roberts JS, Kardia SL, Petty EM. Understandings of basic genetics in the United States: results from a national survey of black and white men and women. Public Health Genomics 2010;13(7-8):467-476

8 Browner $\mathrm{CH}$, Preloran HM, Casado MC, Bass HN, Walker AP. Genetic counseling gone awry: miscommunication between prenatal genetic service providers and Mexican-origin clients. Soc Sci Med 2003;56(09):1933-1946

9 Gammon BL, Kraft SA, Michie M, Allyse M. "I think we've got too many tests!": Prenatal providers' reflections on ethical and clinical challenges in the practice integration of cell-free DNA screening. Ethics Med Public Health 2016;2(03):334-342

10 Jallinoja P, Aro AR. Knowledge about genes and heredity among Finns. New Genet Soc 1999;18:101-110

11 Calsbeek H, Morren M, Bensing J, Rijken M. Knowledge and attitudes towards genetic testing: a two year follow-up study in patients with asthma, diabetes mellitus and cardiovascular disease. J Genet Couns 2007;16(04):493-504

12 Delgado A, Schulkin J, Kaji R, Macri C. Provider knowledge, comfort with and training on genetics screening and diagnostic testing: assessing educational needs. J Reprod Med 2020;65(01):

13 Ryan CL, Bauman K. Educational attainment in the united states: 2015. United States Department of Commerce. 2016. Available at: from:https://www.census.gov/content/dam/Census/library/publications/2016/demo/p20578.pdf 